\title{
Mauriac syndrome — is already a history?
}

\begin{abstract}
In 1930 Mauriac described a syndrome characterized by the presence of growth impairment, hepatomegaly, delayed puberty and cushingoid features in patients with poorly controlled type 1 diabetes mellitus (T1DM). At that time, Mauriac syndrome was a common occurrence. This state was maintained even in the fifties and sixties of the last century. The introduction of modern methods of insulin and glucose monitoring decisively reduced the frequency of occurrence of this syndrome. The incidence of Mauriac syndrome decreased dramatically, although it is still being reported. Often in these cases the patients present only some symptoms of this syndrome. The introduction of diagnostic tests allowed to find the genetic basis of these disorders in some of the cases. (Clin Diabetol 2017; 6, 3: 101-104)
\end{abstract}

Key words: Mauriac syndrome, hepatomegaly, glycogenic hepatopathy, growth retardation, poorly controlled diabetes

\section{Introduction}

Mauriac syndrome is characterized by obesity, growth failure, hepatomegaly and delayed pubertal maturation in patients with insulin-dependent diabetes mellitus. It is associated with poor control of diabetes mellitus. Currently the disease is a rare complication, but it is necessary to pay attention to the possibility of the existence of its individual characteristics. This applies in particular other forms of diabetes than type 1 .

Address for correspondence:

Prof. Ewa Otto-Buczkowska, MD PhD

ul. Jasnogórska 16/21, 44-100 Gliwice

e-mail: em.buczkowski@pro.onet.pl

Clinical Diabetology 2017, 6, 3, 101-104

DOI: $10.5603 /$ DK.2017.0016

Received: 07.06.2017

Accepted: 11.07.2017
The Mauriac team was first described in 1930 [1]. This syndrome was described as a result of poor metabolic control of type 1 diabetes characterized by growth disturbance, delayed puberty, and very significant hepatic enlargement. The occurrence of this syndrome was associated with chronic hyperglycaemia.

The discovery of insulin is considered to be one of the greatest achievements of 20th century medicine. Before the age of insulin, young people with diabetes had no chance of life. Introduction of insulin made it possible to survive, but the duration of life was usually short because it was not possible to monitor blood glucose levels. At that time Mauriac's syndrome was a frequent occurrence until the fifties and sixties of the last century [2-5].

The situation started to change a little when selfcontrol was introduced, based on the detection of sugar and acetone in urine. Mauriac's syndrome was described mainly in children. This was probably related to the fact that older patients, if they were poorly compensated, did not survive. As the treatment options improved, the incidence of this syndrome also decreased. Introducing blood glucose level control, which took place at the end of the 1970s, dramatically increased the ability to control the metabolic compensation. The possibility of at home glycaemia checking was a huge breakthrough in the treatment of diabetes, the second most significant right after the invention of insulin.

In subsequent years, due to the improvement of diabetes treatment, the occurrence of the Mauriac syndrome continued to decrease but the features of this syndrome such as growth disorders, overweight, or delayed maturation were relatively common [6-10].

Monitoring of blood glucose levels has made it possible to fundamentally change the criteria of diabetes control and to introduce intensive insulin therapy. This has played a huge role in the prevention of chronic complications of diabetes, including the reduction of the Mauriac syndrome. Further improvements in metabolic control were the result of better and better 
insulin delivery, improved methods of administration, and improved blood glucose monitoring.

The frequency of the Mauriac syndrome has decreased drastically, however, it is still being described. Children with type 1 diabetes and poor metabolic control are at risk of developing Mauriac syndrome, similar complication may occur in type-1 or type- 2 adult diabetics; namely, glycogenic hepatopathy [11, 12].

Portugese authors presented an analysis of 91 patients with type 1 diabetes mellitus in which 6 patients were diagnosed with Mauriac syndrome [13].

All had a previous history of poor glycemic control before the diagnosis of MS with glycated hemoglobin $\left(\mathrm{HbA}_{1 \mathrm{c}}\right)$ between 8.8 and $12.9 \%$. Increase of hepatic enzymes was present in all the patients; 4 of them had associated hepatomegaly. All the girls presented puberty delay and cushingoid features.

Schmetz et al. described two cases of Mauriac syndrome in which after metabolic control was achieved, reduction of hepatomegaly and the disappearance of cushingoid features were observed, proving the reversibility of the syndrome [14].

An interesting study was presented by American authors who analyzed the cases of Mauriac's syndrome observed for over 30 years [15].

These authors have noted that the use of adequate insulin therapy may cause withdrawal of the symptoms. However, the authors pointed out that insulin therapy cannot be too aggressive because it can lead to a dramatic deterioration of diabetic retinopathy and nephropathy.

One of the symptoms in Mauriac syndrome is hepatomegaly. In a randomized, double-blind, placebocontrolled study in a group of 10 children with type 1 diabetes the most frequent finding was glycogen degeneration of the plasma and nuclei of hepatocytes which agrees with the reports of other authors [16].

A relatively frequent lesion was observed in 4 cases of fatty degeneration of the liver regarded by most authors as a lesion occurring mainly in adult-onset diabetes.

Fitzpatrick et al. presented a histological analysis of the liver in a group of thirty-one young people, median age of 15.1 years and the average duration of diabetes in this group was 10 years [17].

Hepatomegaly was present in $16 \%$ of the cases. Liver biopsy was undertaken in 19 (61\%) ones. Significant steatosis, inflammation and fibrosis were detected in all of the liver biopsies.

English authors, basing on their own observations and review of the literature, have expressed the view that regular abdominal examinations are recommended for all children and young people with long lasting, poorly controlled diabetes $\left(\mathrm{HbA}_{1 c}\right.$ persistently $\left.>9.5 \%\right)$ in the presence of Mauriac syndrome [18].
One of the complications of type 1 diabetes is growth disturbance, which is linked to classic microvascular diabetic complications [19].

\section{Discussion}

Despite advances in medical care of children with T1DM, growth remains suboptimal in this population and likely reflects ongoing metabolic disturbances.

The causes of growth disorders in juvenile type 1 diabetic patients are complex. On the one hand, this is due to the fact that there are still many areas in the world where diabetes treatment is at a very low level.

The cause of liver enlargement in this syndrome is glycogenic hepatopathy. It develops due to excessive accumulation of glycogen in the hepatocytes [20].

It is recommended to differentiate glycogenic hepatopathy from nonalcoholic fatty liver disease (NAFLD), which is the most common cause of chronic liver disease in type 2 diabetes, however it also occurs in type 1 diabetes [21]. The final determination of the nature of hepatomegaly requires liver biopsy $[22,23]$.

Brouwers et al. described a case study of glycogenic hepatopathy co-occurrence with increased hepatic glycogen storage and increased plasma lactate levels [24]. Recently Canadian authors have linked the occurrence of glycogenic hepatopathy with lactic acidosis [25]. These authors claim that further research is required to explain the pathophysiology of lactic acidosis in glycogenic hepatopathy.

In consideration of the pathogenesis of the Mauriac syndrome and accompanying growth disorders, reduced Insulin-like growth factor-1 (IGF-1), IGF binding protein-3 (IGFBP-3) levels and growth hormones levels or production of inactive forms of these hormones are taken into account [26, 27].

The development of genetic research has made it possible to determine the presence of genetic conditions in some cases of the Mauriac syndrome. Such studies have recently been reported by MacDonald et al. [28]. The authors noted that the mutation in PHKG2 (phosphorylase kinase catalytic subunit gamma 2), combined with hyperglycaemia, together with glycogenolysis, caused severe hepatomegaly.

Mauriac syndrome was also described in a case of 9-year-old girl who was diagnosed with neonatal diabetes at 3 months of age due to mutation in KCNJ11 [29].

One of the symptoms of Mauriac syndrome, along with hepatomegaly and growth failure is delayed pubertal maturation. In the unadulterated diabetes, increased levels of advanced glycation end products suppress activation of the gonadotropin-releasing hormone $(\mathrm{GnRH})$ pulse generator, resulting in pubertal delay [30]. 


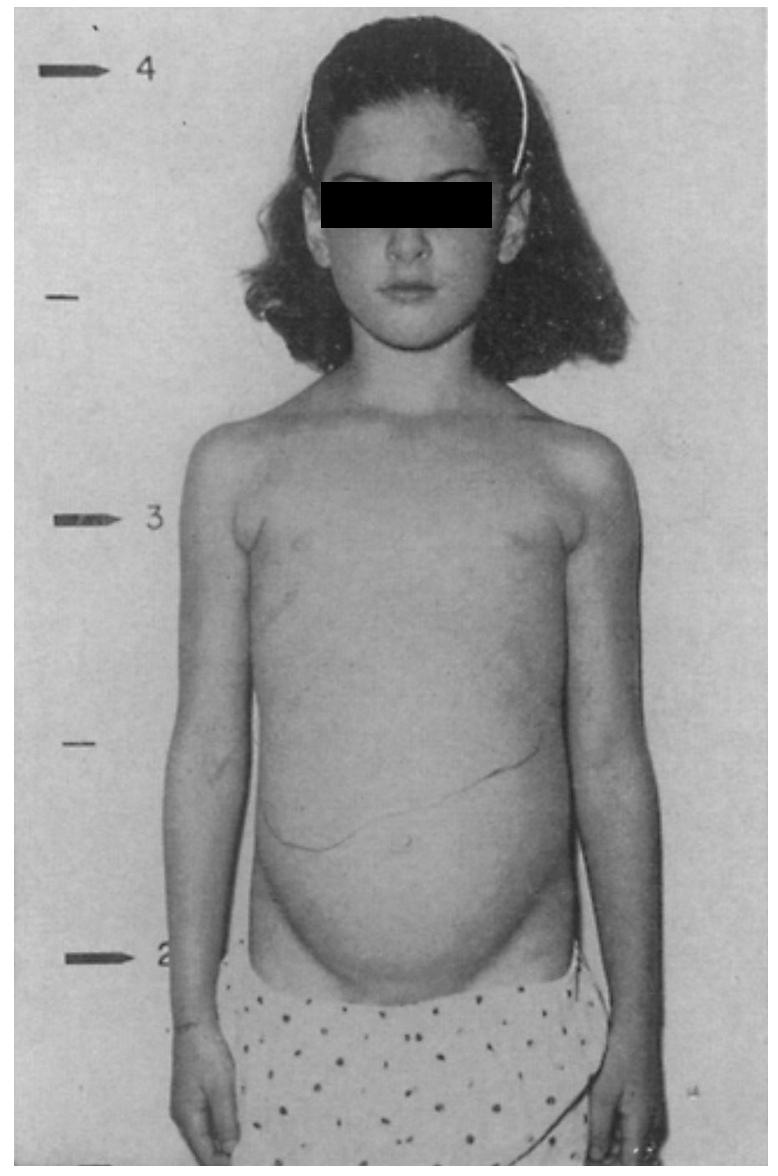

Figure 1. 14.5 years old girl. Type 1 diabetes at 4 years of age, chronic decompensation, $\mathrm{HbA}_{1 \mathrm{c}}$ levels always above $10 \%$. Growth deficiency (3 pcs); high degree of hepatomegaly; lack of maturing features. Picture by Prof. E. Pankowska

One of the characteristics of the Mauriac syndrome is obesity, however, recently some non-obese patients have been reported as well [31].

Mauriac syndrome illustrated by the prints of Polish authors attached with their consent (Fig. 1, 2).

\section{Conclusions}

In early years of insulin therapy, severe growth retardation with pubertal delay, obesity and hepatomegaly such as in Mauriac syndrome, have been reported often in patients with insulin-dependent diabetes mellitus (IDDM). These conditions are now rare due to improvements in insulin delivery and glycaemic control. However, one should pay attention to the possibility of occurrence of individual features of this syndrome. One should also remember that the Mauriac syndrome may occur in other types of diabetes. Syndrome has been described in monogenic forms of diabetes.

It is crucial to be aware of Mauriac syndrome's extreme importance since most clinical features are reversible with better glycaemic control.

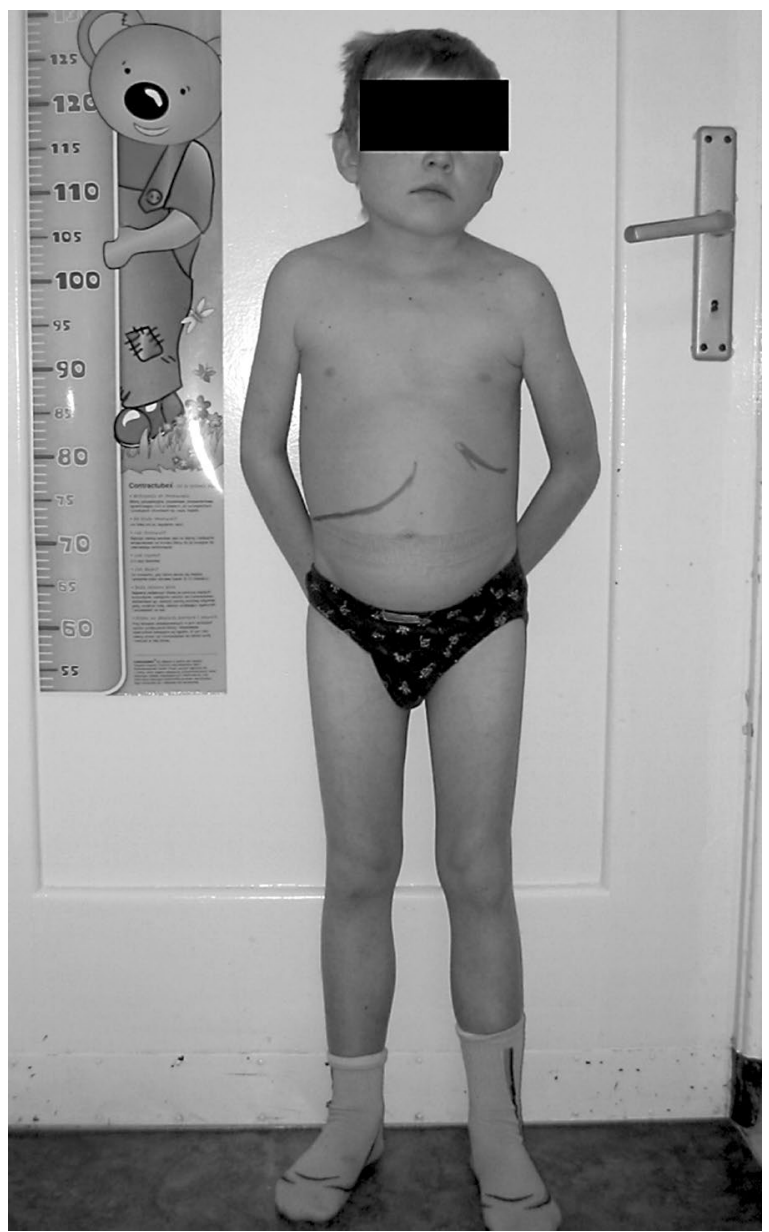

Figure 2. Boy at age 15. Type 1 diabetes at 5 years of age, chronically decompensated. $\mathrm{HbA}_{1 \mathrm{c}}$ levels have never been below $10 \%$. Growth deficiency ( 3 pcs); high degree of hepatomegaly; lack of maturing features. Picture by Prof. A. Noczyńska

\section{REFERENCES}

1. Mauriac P. Gros ventre, hepatomegalie, troubles de croissance chez les enfants diabetiques traites depuis plusiers annee par I'insuline. Gaz Hebd Med Bordeaux. 1930; 26: 402-410.

2. Mandell F, Berenberg W. The Mauriac syndrome. Am J Dis Child. 1974; 127(6): 900-902, doi: 10.1001/archpedi.1974.02110250126021, indexed in Pubmed: 4834782.

3. Najjar S, Ayash MA. The Mauriac syndrome. Clin Pediatr (Phila). 1974; 13(9): 723-725, doi: 10.1177/000992287401300904, indexed in Pubmed: 4416595.

4. Olszowska L, Ludwiczak H. Mauriac syndrome - an ever present problem in infantile diabetes. Pediatr Pol. 1976; 51(8): 931-935, indexed in Pubmed: 967595.

5. Otto-Buczkowska E, Rzepka J, Sońta-Jakimczyk D, et al. Somatic development of diabetic children. Pediatr Pol. 1973; 48(3): 307-315, indexed in Pubmed: 4693964.

6. Bognetti E, Riva MC, Bonfanti R, et al. Growth changes in children and adolescents with short-term diabetes. Diabetes Care. 1998; 21(8): 1226-1229, doi: 10.2337/diacare.21.8.1226, indexed in Pubmed: 9702424.

7. Holl RW, Heinze E, Seifert M, et al. Longitudinal analysis of somatic development in paediatric patients with IDDM: genetic influences on height and weight. Diabetologia. 1994; 37(9): 925-929, doi: 10.1007/s001250050198, indexed in Pubmed: 7806023. 
8. Jackson R. Growth and Maturation of Children with Insulin-Dependent Diabetes Mellitus. Pediatric Clinics of North America. 1984; 31(3): 545-567, doi: 10.1016/s0031-3955(16)34606-5.

9. Jos J, Méteyer I, Farkas D, et al. [Growth of children with insulin-dependent diabetes. Study of 104 cases]. Arch Pediatr. 1996; 3(3): 218-226, indexed in Pubmed: 8785558.

10. Morrison EY, McKenzie K. The Mauriac syndrome. West Indian Med J. 1989; 38(3): 180-182, indexed in Pubmed: 2694619.

11. Madhu SV, Jain R, Kant S, et al. Mauriac syndrome: A rare complication of type 1 diabetes mellitus. Indian J Endocrinol Metab. 2013; 17(4): 764-765, doi: 10.4103/2230-8210.113780, indexed in Pubmed: 23961505.

12. Oeschgef VV, Prieto M. Mauriac syndrome in Argentina in the XXI century: series of 5 cases. Arch Argent Pediatr. 2014; 112(2): e46e49, doi: 10.5546/aap.2014.e46, indexed in Pubmed: 24584799.

13. Dias J, Martins S, Carvalho $S$, et al. Mauriac syndrome still exists. Endocrinol Nutr. 2013; 60(5): 245-248, doi: 10.1016/j. endonu.2012.12.005, indexed in Pubmed: 23540612.

14. Schmetz AVN, Dekker-Maas MH, den Breejen MP, et al. Mauriac syndrome - a rare complication of type 1 diabetes mellitus. Ned Tijdschr Geneeskd. 2012; 156(28): A4678, indexed in Pubmed: 22805790.

15. Kim MS, Quintos JB. Mauriac syndrome: growth failure and type 1 diabetes mellitus. Pediatr Endocrinol Rev. 2008; 5 Suppl 4: 989-993, indexed in Pubmed: 18806715.

16. Otto-Buczkowska E, Smigla K, Sliwa F. Microscopic liver pattern in diabetic children. Wiad Lek. 1974; 27(24): 2111-2114, indexed in Pubmed: 4439911.

17. Fitzpatrick E, Cotoi C, Quaglia A, et al. Hepatopathy of Mauriac syndrome: a retrospective review from a tertiary liver centre. Arch Dis Child. 2014; 99(4): 354-357, doi: 10.1136/archdischild-2013-304426, indexed in Pubmed: 24412980.

18. Elder CJ, Natarajan A. Mauriac syndrome - a modern reality. J Pediatr Endocrinol Metab. 2010; 23(3): 311-313, doi: 10.1515/ /jpem.2010.23.3.311, indexed in Pubmed: 20480733.

19. Mitchell DM. Growth in patients with type 1 diabetes. Curr Opin Endocrinol Diabetes Obes. 2017; 24(1): 67-72, doi: 10.1097/ /MED.0000000000000310, indexed in Pubmed: 27898589.

20. Al Sarkhy AA, Zaidi ZA, Babiker AM. Glycogenic hepatopathy, an underdiagnosed cause of relapsing hepatitis in uncontrolled type 1 diabetes mellitus. Saudi Med J. 2017; 38(1): 89-92, doi: 10.15537/smj.2017.1.15934, indexed in Pubmed: 28042636

21. Atmaca M, Ucler R, Kartal M, et al. Glycogenic Hepatopathy in Type 1 Diabetes Mellitus. Case Reports Hepatol. 2015; 2015:
236143, doi: $10.1155 / 2015 / 236143$, indexed in Pubmed: 26347835.

22. Giordano S, Martocchia A, Toussan L, et al. Diagnosis of hepatic glycogenosis in poorly controlled type 1 diabetes mellitus. World J Diabetes. 2014; 5(6): 882-888, doi: 10.4239/wjd.v5.i6.882, indexed in Pubmed: 25512791.

23. Hernández-Quiles $C$, Fernández-Ojeda MR, Solanilla Rodríguez R, et al. Mauriac syndrome: a liver disease that differs from steatosis of diabetes. Rev Clin Esp (Barc). 2013; 213(3): 169-170, doi: 10.1016/j.rce.2012.10.003, indexed in Pubmed: 23261838.

24. Brouwers MC, Ham JC, Wisse E, et al. Elevated lactate levels in patients with poorly regulated type 1 diabetes and glycogenic hepatopathy: a new feature of Mauriac syndrome. Diabetes Care. 2015; 38(2): e11-e12, doi: 10.2337/dc14-2205, indexed in Pubmed: 25614691.

25. Deemer KS, Alvarez GF. A Rare Case of Persistent Lactic Acidosis in the ICU: Glycogenic Hepatopathy and Mauriac Syndrome. Case Rep Crit Care. 2016; 2016: 6072909, doi: 10.1155/2016/6072909, indexed in Pubmed: 27699071.

26. Jung InAh, Cho WK, Jeon YJ, et al. Hepatic glycogenosis in type 1 diabetes mellitus mimicking Mauriac syndrome. Korean J Pediatr. 2015; 58(6): 234-237, doi: 10.3345/kjp.2015.58.6.234, indexed in Pubmed: 26213553.

27. Nagesh VS, Kalra S. Type 1 diabetes: Syndromes in resourcechallenged settings. J Pak Med Assoc. 2015; 65(6): 681-685, indexed in Pubmed: 26060173.

28. MacDonald MJ, Hasan NM, Ansari IUH, et al. Discovery of a Genetic Metabolic Cause for Mauriac Syndrome in Type 1 Diabetes. Diabetes. 2016; 65(7): 2051-2059, doi: 10.2337/db16-0099, indexed in Pubmed: 27207549.

29. Chaiudom R, Sahakitrungruang T, Wacharasindhu S, et al. A girl with permanent neonatal diabetes due to KCNJ11 mutation presented with Mauriac syndrome after improper adjustment in sulfonylurea dosage over 6 years. Journal of Pediatric Endocrinology and Metabolism. 2016; 29(9), doi: 10.1515/jpem2016-0065.

30. Chowdhury S. Puberty and type 1 diabetes. Indian Journal of Endocrinology and Metabolism. 2015; 19(7): 51, doi: 10.4103/22308210.155402.

31. Gutch M, Philip R, Saran S, et al. Re-emergence of a rare syndrome: A case of Mauriac syndrome. Indian J Endocrinol Metab. 2013; 17(Suppl 1): S283-S285, doi: 10.4103/2230-8210.119611, indexed in Pubmed: 24251187. 